\title{
Avaliação de empreendimentos habitacionais de interesse social com base na hierarquia de valor percebido pelo usuário
}

\author{
Evaluation of social housing projects based on the user \\ perceived value hierarchy
}

\section{Fernanda Sbaraini Bonatto \\ Luciana Inês Gomes Miron \\ Carlos Torres Formoso}

\section{Resumo}

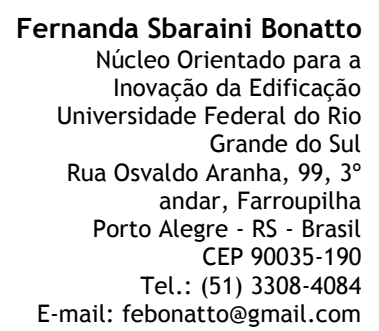

Luciana Inês Gomes Miron Departamento de Arquitetura, Faculdade de Arquitetura Universidade Federal do Rio Grande do Sul

Av. Sarmento Leite, 320 , Centro

Porto Alegre - RS - Brasil CEP 90050-170

Tel.: (51) 3308-3124 E-mail: luciana.miron@ufrgs.br

Carlos Torres Formoso Núcleo Orientado para a Inovação da Edificação Universidade Federal do Rio Grande do Sul E-mail: formoso@ufrgs.br

Recebido em 03/11/2010 Aceito em 10/03/2011
A avaliação de empreendimentos tem grande importância no esforço de melhoria da habitação de interesse social, podendo auxiliar na avaliação de resultados e na identificação de erros e acertos ante os objetivos e ações do projeto. No entanto, a diversidade e dinâmica de programas habitacionais e a falta de clareza nos objetivos dos empreendimentos podem dificultar o processo de avaliação desse tipo de produto. Com frequência, as avaliações realizadas nos empreendimentos de habitação de interesse social têm como foco os atributos do produto, sem estabelecer uma conexão com os objetivos esperados. Neste artigo, propõe-se um modelo para estruturar as avaliações de empreendimentos habitacionais de interesse social, adotando uma hierarquia de valor que vincula os atributos às suas consequências de uso e aos objetivos esperados. O modelo não está limitado a um programa habitacional específico e parte da ideia de produto ampliado, ou seja, não está focado apenas no produto habitação. As principais contribuições do estudo referem-se ao mapeamento do produto habitacional e à identificação de influências entre os atributos do produto avaliados e os resultados esperados pelos gestores e percebidos pelos usuários.

Palavras-chave: Modelo de avaliação. Avaliação pós-ocupação. Empreendimento habitacional de interesse social. Hierarquia de valor.

\section{Abstract}

The evaluation of projects is very important for the effort of improving social housing, making it possible to support the assessment of results, and the identification of errors and achievements in relation to the project objectives and actions. However, the diversity and dynamics of housing programs and the lack of clarity in project objectives may hinder the evaluating process of this type of product. Often, the evaluation of social housing projects is focused on product attributes, without establishing a clear connection with the expected objectives. In this paper, a model for structuring the evaluation of social housing projects is proposed, adopting a value hierarchy that links the attributes to the consequences of use and intended goals. This model is not aimed to a specific housing program, and is based on the idea of extended products, i.e. it is not limited to the physical products. The main contributions of the study refer to the mapping of the social housing product, as well as to the identification of influences between the assessment of the product attributes, and the results expected by managers and perceived by customers.

Keywords: Evaluation model. Post-occupancy evaluation. Social housing projects. Value hierarchy. 


\section{Introdução}

Os empreendimentos habitacionais de interesse social $^{1}$ (EHIS) têm sido alvo de diversos estudos realizados no meio acadêmico. Em uma visão ampla, a busca de melhores resultados em relação a esses empreendimentos, além de gerar benefícios aos seus usuários, também visa a melhorias para a sociedade (IPEA, 2007). Os EHIS têm importantes implicações no desenvolvimento das cidades e na qualidade de vida que elas proporcionam aos seus cidadãos. No entanto, de forma geral, para que haja os benefícios para a sociedade são necessários bons resultados na relação entre o usuário (consumidor) e o produto oferecido no âmbito dos programas habitacionais pelos diferentes agentes envolvidos (fornecedor). Dessa forma, e também considerando os recursos investidos em programas habitacionais, destaca-se a importância da formação da satisfação e da geração de valor para a população atendida, a fim de que realmente esses benefícios ocorram de forma duradoura.

Para Koskela (2000), no desdobramento das relações cliente ${ }^{2}$-fornecedor, o valor é gerado pelo fornecedor para o cliente mediante o atendimento dos requisitos desse cliente. Segundo esse autor, a geração de valor ainda é um conceito insuficientemente disseminado e entendido na construção civil. A falta de um referencial teórico mais adequado e consistente é apontada como uma das causas e, a partir disso, diversos estudos têm buscado, em diversos campos do conhecimento, referenciais que auxiliem no entendimento sobre a geração de valor e sua aplicação no contexto da construção (KOSKELA, 2000; LEINONEN; HUOVILA, 2000; BARLOW; OZAKI, 2003; MIRON, 2008). Nesse sentido, a área de marketing destaca-se pela evolução na mensuração de importantes constructos relacionados à geração de valor, tais como satisfação, valor percebido, benefícios e retenção. Exemplo disso, as pesquisas sobre o comportamento do consumidor constituem um importante referencial para o entendimento da percepção da satisfação de usuários de produtos (PINHEIRO et al., 2005).

Segundo Way e Bordass (2005), a indústria da construção civil é lenta em aprendizagem sobre como atingir uma maior satisfação dos seus consumidores. Gann, Salter e Whyte (2003)

\footnotetext{
${ }^{1}$ Nesta pesquisa, entende-se por EHIS os empreendimentos desenvolvidos, de forma integral ou parcial, com subsídios do poder público a partir de programas habitacionais. Segundo Brasil (2010), nessa situação se enquadram empreendimentos destinados a beneficiários com renda entre 0 e 6 salários mínimos.

${ }^{2}$ Neste artigo, o foco dos estudos é o cliente final da construção civil, ou seja, o consumidor que irá morar no empreendimento, também denominado de usuário.
}

explicam que, visando à melhoria dessa situação, são necessárias tanto mudanças na cultura e práticas do processo, quanto o desenvolvimento de instrumentos de apoio. Para tanto, a etapa de uso dos empreendimentos é a mais propícia em aprendizagem sobre como atingir uma maior satisfação do consumidor (WAY; BORDASS, 2005), sendo as avaliações uma possibilidade para visualização de resultados diante dos objetivos de ações realizadas (BORDASS; LEAMAN, 2005). Com essas avaliações, muito pode ser aprendido e retroalimentado para a melhoria de futuros projetos.

No entanto, no contexto de EHIS, analisando avaliações pós-ocupação (APO) realizadas no meio acadêmico, é possível perceber, através da repetição dos problemas identificados ao longo dos anos, que as informações e oportunidades para melhorias não são devidamente consideradas na realização de novos empreendimentos (ORNSTEIN; CRUZ, 2000; ROMERO; VIANNA, 2002; MORAES; ABIKO, 2006; LIMA, 2007). Segundo Vischer (2009), a retroalimentação a partir desse tipo de avaliação geralmente não ocorre na prática da construção civil e, assim, os resultados acabam permanecendo apenas na área acadêmica, sem ser consultados por profissionais. Nesse sentido, Bordass (2003) afirma que, de forma a possibilitar os benefícios esperados com essas avaliações e torná-las uma prática, é necessário envolver as organizações no processo de avaliação.

Diante dessa consideração, um fato que deve ser ressaltado é que no contexto de provisão habitacional há a previsão de avaliações dos empreendimentos entregues no âmbito dos diversos programas que são operados pela Caixa Econômica Federal (CAIXA). Essa previsão evidencia uma oportunidade de tornar a avaliação dos EHIS em uso uma prática, envolvendo agentes do processo e proporcionando aprendizagem e melhoria em novos empreendimentos, de forma a contribuir para a geração de valor.

Ainda, Woodruff e Gardial (1996) salientam que, no desenvolvimento de avaliações, geralmente os clientes são questionados apenas acerca dos atributos do produto. Segundo os referidos autores, de forma a possibilitar um maior entendimento sobre a geração de valor para esses usuários, é necessário que as consequências do produto em uso e os objetivos esperados também sejam explorados, explicitando os diferentes níveis de abstração na percepção dos resultados. Como os objetivos e as consequências esperados para os EHIS nem sempre são explicitados, é necessário 
que estudos de avaliação de empreendimentos auxiliem na visualização dos resultados esperados e obtidos, estreitando a relação cliente-fornecedor.

Assim, com embasamento teórico vinculado principalmente à área de marketing, o objetivo deste artigo é apresentar e descrever um modelo proposto para a avaliação de EHIS a partir da percepção de usuários, buscando:

(a) vincular a satisfação dos clientes finais em relação a atributos do produto com os principais impactos dos EHIS;

(b) ser adaptável à diversidade e dinâmica dos programas habitacionais; $\mathrm{e}$

(c) envolver agentes, promotores e financiadores no processo de avaliação.

Esse modelo foi desenvolvido visando à sua possível aplicação por agentes envolvidos no desenvolvimento de EHIS e não se trata de uma avaliação pós-ocupação completa, uma vez que está focado principalmente na percepção do usuário. Cabe salientar que este artigo é derivado da dissertação de mestrado da primeira autora (BONATTO, 2011), pesquisa integrante do projeto Sistema de Indicadores de Qualidade e Procedimentos para Retroalimentação na Habitação de Interesse Social ${ }^{3}$ (QualiHIS), desenvolvido pelo grupo de estudos em Gerenciamento e Economia da Construção do Núcleo Orientado para a Inovação da Edificação (NORIE) da Universidade Federal do Rio Grande do Sul (UFRGS).

\section{Percepção de valor do produto}

Produto é o principal resultado de uma organização, um bem manufaturado, um serviço ou ambos. Lovelock e Wright (2002) definem bens como os objetos ou dispositivos físicos que fornecem benefícios aos clientes através de propriedade ou uso, e serviço como uma ação ou desempenho que gera benefícios aos clientes através da sua efetivação e não resulta em propriedade. Embora às vezes a produção do serviço possa estar ligada a um produto físico, a sua característica é essencialmente intangível (LOVELOCK; WRIGHT, 2002). Na perspectiva do usuário, Woodruff e Gardial (1996) explicam que produtos são meios para um fim. Dessa forma,

\footnotetext{
${ }^{3}$ O projeto QualiHIS, desenvolvido entre 2007 e 2009, foi financiado pelo programa HABITARE, com recursos do CNPq e da FINEP, com contrapartida da Caixa Econômica Federal e órgãos promotores de construção habitacional. O objetivo principal foi o desenvolvimento de instrumentos para que os principais agentes envolvidos nos programas habitacionais possam avaliar a qualidade do processo e do produto final. O projeto QualiHIS é parte de uma rede de pesquisa, na qual também foram desenvolvidos projetos pelas instituições IPT, USP, UEL, UFPEL, UNICAMP, UFSC e UFCG.
}

os mesmos autores explicam que a entrega de valor ao cliente está vinculada ao exato entendimento do que é o valor desejado por esses clientes.

$\mathrm{Na}$ literatura, diversas são as definições de valor para o cliente. Um fato relevante é que, segundo Woodruff (1997), apesar dessa diversidade, existem similaridades entre conceitos, como o fato de o valor estar relacionado ao uso de um produto, ser percebido apenas por consumidores e envolver um julgamento entre o que o consumidor recebe (qualidade, benefícios, valor financeiro) e entrega ao adquirir e usar o produto (preço, sacrifícios).

Na definição de Zeithaml (1988), valor percebido é entendido como uma avaliação global do consumidor sobre a utilidade de um produto com base na percepção do que é recebido e do que é entregue, representando um julgamento entre benefícios e sacrifícios. Esse julgamento é explicado por Monroe (1990) por meio de uma equação, na qual o valor percebido pelo cliente é a razão entre benefícios e sacrifícios percebidos, basicamente entendidos como qualidade e preço.

Segundo Miller e Swaddling (2002), o julgamento final de valor envolve também comparações com produtos alternativos. Anderson, Jain e Chintagunta (1993) corroboram essa visão ao afirmarem que o valor percebido é inerente ao contexto competitivo, levando em consideração outros produtos e preços disponíveis.

Segundo Holbrook (2006), o valor pode ser extrínseco, que reflete o aspecto utilitarista ou instrumental de algo como um meio para um fim específico, ou intrínseco, que representa a perspectiva emocional do consumo. Segundo o mesmo autor, o valor também pode ser orientado ao âmbito próprio (para o consumidor ou em virtude do efeito sobre ele) ou alheio (para os outros ou em virtude do efeito sobre eles). Combinando esses aspectos, são apresentados os seguintes tipos de valor:

(a) econômico, quando o produto ou a experiência de consumo servem como um meio para os objetivos do consumidor;

(b) social, quando o consumo serve como um meio para moldar as respostas dos outros;

(c) hedônico, que surge a partir do prazer de consumir; e

(d) altruístico, que implica a preocupação de como o consumo afeta os outros (HOLBROOK, 2006).

Outra discussão importante relacionada ao conceito de valor percebido é sobre a distinção entre os significados de valor e valores. Segundo Holbrook (2006), valor é o resultado de um 
julgamento, enquanto o termo "valores" é referente aos padrões, regras, critérios, normas, objetivos ou ideais que servem como base para esse julgamento, refletindo as diferenças individuais do consumidor. Assim, a percepção de valor dos clientes sobre um mesmo produto pode ser diferente (ZEITHAML, 1988; EGGERT; ULAGA, 2002; HOLBROOK, 2006), estando relacionado tanto com as necessidades e preferências pessoais, quanto com os recursos financeiros de cada cliente (RAVALD; GRÖNROOS, 1996).

Woodruff e Gardial (1996) interligam os conceitos de valor e valores. Segundo esses autores, o julgamento de valor envolve relações entre o que é oferecido (produto, serviço), a situação de uso e o usuário (valores, metas). A proposta dos referidos autores segue uma estrutura hierárquica, com níveis de abstração e relevância para o cliente. Esse modelo é apresentado em três níveis (WOODRUFF; GARDIAL 1996):

(a) atributos: referentes ao nível mais concreto, são as características físicas, recursos ou componentes de um produto, geralmente mencionados na sua descrição e podendo também ser entendidos como as opções oferecidas. Atributos podem ser tangíveis ou intangíveis e tendem a ser definidos objetivamente, podendo haver vários atributos ou conjuntos de atributos que compõem determinado produto;

(b) consequências de uso: são considerações subjetivas dos resultados e experiências, positivas ou negativas, do produto em uso, ou seja, é o que acontece quando o produto é usado. 4

Consequências são geralmente mencionadas na descrição das experiências com o produto. Uma consequência pode estar relacionada com um atributo ou ser o resultado da combinação de vários atributos. Também podem existir relações entre consequências em diferentes níveis;

(c) objetivos: correspondem ao nível mais abstrato da hierarquia de valor, estando relacionados com os principais valores dos clientes, com os fins últimos atendidos pelo produto.

Para desenvolver essa estrutura conceitual, Woodruff e Gardial (1996) se embasaram no modelo means-end (meios-fins), desenvolvido por Gutman (1982). O modelo meios-fins foi desenvolvido para descrever como consumidores categorizam as informações sobre os produtos na memória, visando a entender o comportamento que leva a escolha de compra (GUTMAN, 1982).

\footnotetext{
${ }^{4}$ Wooduff e Gardial (1996) sugerem que as consequências de uso podem ser classificadas em valor de posse, relativo a aspectos simbólicos como o status ou o prestígio vinculados ao produto, e valor de uso, referente a questões utilitárias do consumo.
}

Woodruff e Gardial (1996) ampliaram a aplicabilidade do modelo meios-fins, considerando, além do valor desejado na compra, o valor recebido durante o uso do produto.

Segundo Gutman (1982), a proposta hierárquica de valor visa a identificar os valores dos consumidores, bem como o potencial que determinados produtos (meios) têm de atender a tais valores (fins) por meio dos seus atributos. Woodruff e Gardial (1996) salientam que existem diversos benefícios na utilização da hierarquia de valor. Entre os benefícios apontados por esses autores estão a possibilidade de entender o que os clientes querem e de guiar as tomadas de decisão sobre alterações e definições de produto pelas consequências e objetivos esperados por esses clientes. Essa abordagem muda a perspectiva sobre o desenvolvimento do produto, que, ao invés de ser ascendente, ou seja, pensada a partir dos atributos, é guiada de cima para baixo, a partir dos objetivos (WOODRUFF; GARDIAL, 1996).

As contribuições desses referenciais teóricos podem ser considerados também no âmbito do mercado habitacional de interesse social. Nesse contexto, as singularidades do produto EHIS podem ser expressas por meio das características intrínsecas à construção civil e da complexidade de possibilidades e relações que apresentam com os usuários e o solo urbano. O esclarecimento dessas diferenças é importante, uma vez que influenciam na aplicação dos conceitos derivados de outras indústrias (BARLOW; OZAKI, 2003), situação que ocorre nesta pesquisa. Nesse sentido, cabe salientar que alguns estudos têm buscado esse entendimento e a operacionalização de conceitos sobre a geração de valor, tais como o desenvolvido por Miron (2008), utilizado como ponto de partida do presente estudo, e Granja et al. (2009).

\section{Método de pesquisa}

Para o desenvolvimento deste estudo adotou-se a estratégia de pesquisa construtiva (constructive research ou design research). Segundo Lukka (2003), essa estratégia caracteriza-se por:

(a) foco em problemas do mundo real com relevância de serem resolvidos na prática;

(b) produção de um artefato inovador de forma a resolver esses problemas;

(c) tentativa de implementação do artefato desenvolvido para testar a aplicabilidade;

(d) estreito envolvimento e cooperação entre pesquisador e profissionais, possibilitando a aprendizagem baseada na experiência; 


\begin{tabular}{|c|c|c|c|c|c|c|c|c|}
\hline 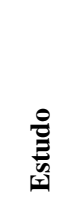 & 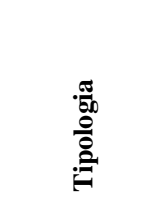 & 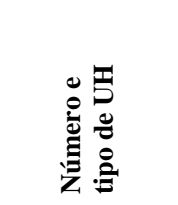 & 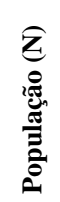 & 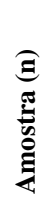 & 氖 & 焉 & 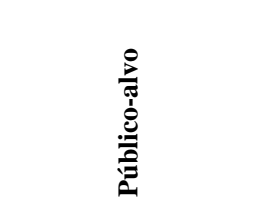 & 遶 \\
\hline $\begin{array}{c}\text { EHIS } \\
1\end{array}$ & $\begin{array}{l}\text { Edifício } \\
\text { reformado } \\
\text { com } 8 \\
\text { pavimentos }\end{array}$ & $\begin{array}{c}42 \\
\text { apartamentos }\end{array}$ & 36 & 27 & $\begin{array}{l}\text { Porto } \\
\text { Alegre }\end{array}$ & $\begin{array}{l}\text { Crédito } \\
\text { Solidário }\end{array}$ & $\begin{array}{c}\text { Famílias organizadas } \\
\text { de forma associativa } \\
\text { com renda mensal de } \\
\text { até } \mathrm{R} \$ 1.125,00 \\
\text { (até } \mathrm{R} \$ 1.900,00 \mathrm{em} \\
\text { casos especiais) } \\
\end{array}$ & $\begin{array}{l}\text { Administração } \\
\text { do EHIS } \\
\text { organizada de } \\
\text { forma } \\
\text { participativa }\end{array}$ \\
\hline$\underset{2}{\text { EHIS }}$ & $\begin{array}{c}\text { Condomínio } \\
\text { vertical com } \\
6 \text { blocos de } \\
5 \text { pavimentos }\end{array}$ & $\begin{array}{c}469 \\
\text { apartamentos }\end{array}$ & 469 & 80 & $\begin{array}{l}\text { Porto } \\
\text { Alegre }\end{array}$ & PAR & $\begin{array}{c}\text { Famílias com renda } \\
\text { mensal de até } \\
\mathrm{R} \$ 1.800,00 \text { (ou até } \\
\mathrm{R} \$ 2.400,00 \text { em casos } \\
\text { especiais) }\end{array}$ & $\begin{array}{l}\text { Grande dimensão } \\
\text { do EHIS }\end{array}$ \\
\hline \multirow{2}{*}{$\begin{array}{c}\text { EHIS } \\
3\end{array}$} & \multirow{2}{*}{ Loteamento } & 156 sobrados & 156 & 60 & \multirow{2}{*}{$\begin{array}{c}\text { Novo } \\
\text { Hamburgo }\end{array}$} & \multirow{2}{*}{$\begin{array}{c}\text { Programa } \\
\text { Urbanização, } \\
\text { Regularização e } \\
\text { Integração de } \\
\text { Assentamentos } \\
\text { Precários }\end{array}$} & \multirow{2}{*}{$\begin{array}{c}\text { Famílias com renda } \\
\text { mensal de até } \\
\mathrm{R} \$ 1.050,00 \text { (mínimo } \\
60 \% \text { dos } \\
\text { beneficiários) }\end{array}$} & \multirow{2}{*}{$\begin{array}{l}\text { Reassentamento } \\
\text { habitacional } \\
\text { realizado pela } \\
\text { Prefeitura }\end{array}$} \\
\hline & & 9 casas térreas & 7 & 7 & & & & \\
\hline
\end{tabular}

Quadro 1 - Empreendimentos e programas habitacionais dos estudos realizados

(e) associação explícita ao conhecimento teórico prévio; e

(f) especial atenção à reflexão dos resultados, retornando para a teoria.

Buscando um aprofundamento sobre o contexto de pesquisa, inicialmente se buscou estudar os programas atualmente operados pela CAIXA que têm no seu escopo o desenvolvimento de EHIS. Esse estudo foi realizado através de análise de arquivos e entrevistas com agentes envolvidos.

Posteriormente, desenvolveu-se o modelo conceitual para guiar a avaliação. Para tanto, buscou-se operacionalizar conceitos da área de marketing, principalmente sobre a hierarquia de valor. Como parte do modelo, foi identificado um conjunto de constructos para representar a percepção dos usuários sobre EHIS em uso, que serviram de ponto de partida para o desenvolvimento de um instrumento de coleta de dados.

O conjunto de constructos foi gerado a partir da categorização por afinidade das respostas qualitativas dos usuários sobre melhores e piores características de EHIS em pesquisas anteriores do NORIE, ${ }^{5}$ isto é, a partir de dados secundários. Para o desenvolvimento do instrumento de coleta de dados também foram utilizadas como base essas

\footnotetext{
${ }^{5}$ Foram utilizados dados dos projetos REQUALI - Gerenciamento de Requisitos e Melhoria da Qualidade na Habitação de Interesse Social, desenvolvido entre 2003 e 2006, e QualiHIS. Os dados são relativos a avaliações realizadas com usuários de EHIS dos programas Operações Coletivas, Programa de Arrendamento Residencial (PAR) e do Projeto Integrado Entrada da Cidade (PIEC).
}

pesquisas anteriores, e na definição das informações que deveriam ser coletadas levaramse em consideração aspectos levantados nas entrevistas com técnicos da CAIXA.

Durante o processo de construção do modelo foram realizadas quatro apresentações, originando discussões e contribuições para essa fase da pesquisa. As discussões foram realizadas com técnicos sociais da CAIXA e com pesquisadores do NORIE com experiência em avaliações de EHIS. Nas discussões eram apresentados o modelo conceitual, o conjunto de constructos e o instrumento para a coleta de dados.

Como parte do processo de desenvolvimento e aprimoramento do modelo, foram realizados três estudos de forma sequencial em EHIS de diferentes programas habitacionais. Essa diversidade de EHIS avaliados foi uma necessidade da pesquisa, uma vez que o modelo de avaliação não deveria estar focado em um programa habitacional específico. Para tanto, foram definidos juntamente com técnicos da CAIXA os empreendimentos que foram avaliados na pesquisa, sendo esses apresentados no Quadro 1 , bem como as características que nortearam a sua escolha.

Para a implementação do modelo de avaliação nos três EHIS selecionados, desenvolveu-se um questionário personalizado para cada estudo. Considerou-se como população de cada empreendimento apenas as unidades habitacionais ocupadas. Após o cálculo do tamanho da amostra, a aplicação dos questionários foi realizada de 
forma presencial. As equipes de coleta visitaram os EHIS e entrevistaram os moradores das unidades habitacionais selecionadas.

A implementação do modelo de avaliação nos três empreendimentos contou com a participação de técnicos sociais da CAIXA. Na avaliação dos EHIS 1 e 2, essa participação ocorreu com um envolvimento menor dos técnicos da CAIXA, que participaram fornecendo informações. Já na avaliação do EHIS 3, buscou-se um envolvimento maior desses técnicos.

\section{Resultados e discussão}

Os principais resultados da pesquisa são referentes às contribuições do modelo proposto para a avaliação. Nesse sentido, inicialmente o modelo é apresentado, seguido de um roteiro proposto para a sua implementação e dos principais resultados dos estudos realizados para o seu desenvolvimento.

\section{Modelo para a avaliação}

O modelo conceitual proposto para a avaliação de EHIS adota a hierarquia de valor para o cliente final, conforme é apresentado na Figura 1. Da mesma forma que proposto por Gutman (1982) e Woodruff e Gardial (1996), existem diferentes níveis de abstração, do mais concreto ao mais abstrato, desde o produto EHIS, passando pelas suas consequências específicas, até o nível mais alto, representado pelos objetivos.

$\mathrm{Na}$ base do modelo está o escopo do produto EHIS, sendo definido pelo que compõe o empreendimento, produtos físicos e serviços. $\mathrm{Na}$ composição do produto EHIS adotaram-se as seguintes definições:

(a) unidade habitacional: edificação ou parcela desta destinada a habitação unifamiliar, podendo ser de diferentes tipologias - casa, sobrado ou apartamento;

(b) áreas de uso comum: são as áreas do condomínio ou loteamento destinadas ao uso comum, podem ser espaços abertos ou fechados, ou, ainda, edificações inteiras, tais como salão de festas, estacionamentos, praças, etc.;

(c) entorno: intrínseco à unidade habitacional ou empreendimento, caracteriza-se pela localização e inserção urbana, refletindo aspectos como os referentes à infraestrutura ou acesso a equipamentos urbanos;

(d) projeto social: referente ao projeto do Trabalho Técnico Social (TTS), envolve diversas ações, que variam conforme o programa ou empreendimento habitacional, tais como as informativas, de mobilização e organização dos beneficiários, de educação ambiental ou patrimonial e, ainda, de capacitação profissional e geração de trabalho e renda; e

(e) gestão do uso: são os aspectos referentes à operação e manutenção dos empreendimentos, considerando as diferentes possibilidades de gestão do uso, como a prestada por administradora ou desenvolvida por autogestão.

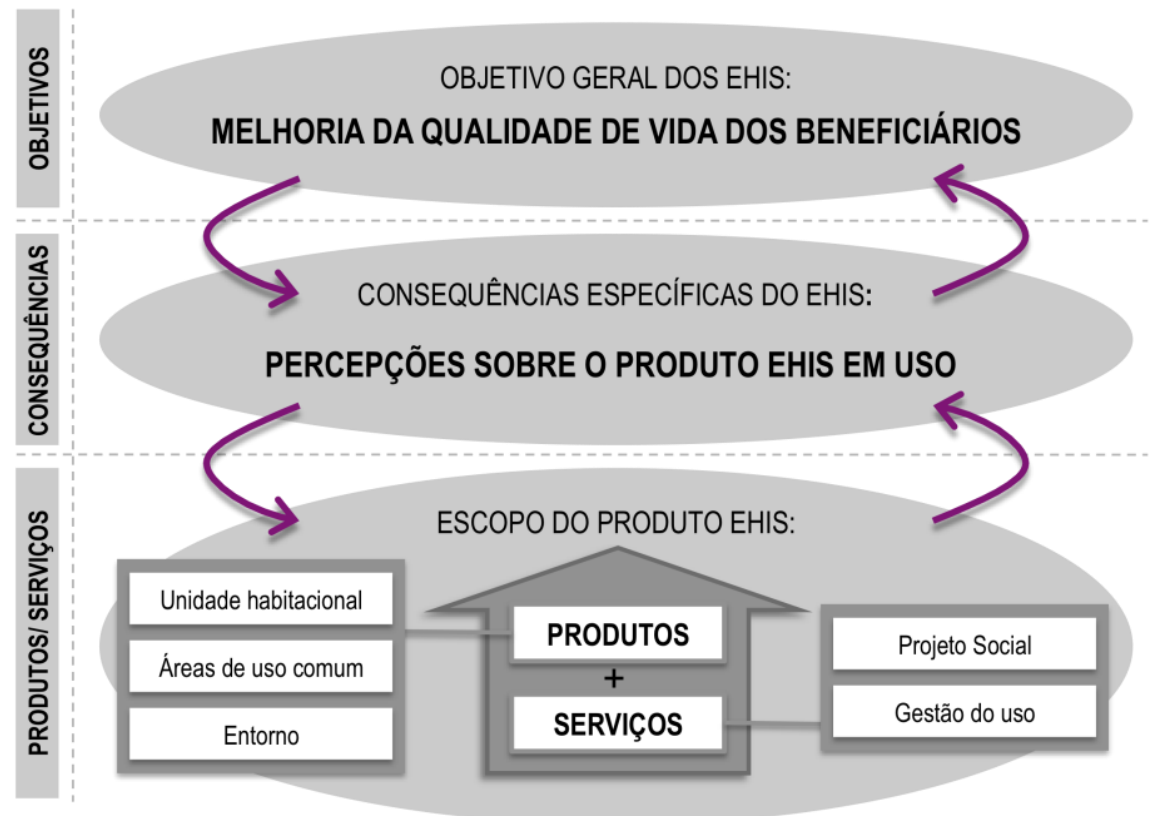

Figura 1 - Modelo conceitual para avaliação de EHIS baseada na hierarquia de valor para o cliente final 
Cabe salientar que a escala do escopo do produto ou o número de componentes podem variar de acordo com o programa ou empreendimento específico. Por ser o nível mais concreto, o escopo do produto é o mais fácil de ser identificado entre os níveis da hierarquia.

A partir da identificação do escopo do produto são derivadas as consequências específicas do EHIS. Considerando que os objetos das avaliações eram EHIS em uso, definiu-se pela obtenção de dados relativos ao nível das consequências, conforme sugerido por Woodruff e Gardial (1996). As consequências esperadas para os usuários de um empreendimento, na visão dos agentes envolvidos no seu desenvolvimento, podem ser identificadas nos documentos sobre os programas habitacionais e a partir da proposta e de ações realizadas, entre outras formas. Já as consequências percebidas podem ser entendidas como fruto das experiências dos usuários com o EHIS. Dessa forma, é possível que existam consequências percebidas não esperadas pelos agentes, bem como consequências planejadas que não sejam percebidas pelo usuário.

Diante dessa situação, foram analisadas percepções de usuários sobre diferentes EHIS, sendo identificadas similaridades, a partir das quais foi proposto um conjunto de constructos para as avaliações. Buscou-se identificar, a partir do escopo do produto, as consequências esperadas que possam guiar a avaliação. Durante as avaliações devem ser identificadas as vinculações entre níveis ou entre consequências. A partir das percepções sobre o EHIS em uso é possível identificar também em que aspectos os objetivos propostos estão sendo atingidos.

No âmbito dos programas habitacionais estudados, constatou-se que, em geral, os EHIS têm como objetivo superior a melhoria da qualidade de vida dos usuários (beneficiários). Isso foi evidenciado nas entrevistas e nos documentos analisados, bem como em um estudo do IPEA (2007). Entretanto, o significado da melhoria da qualidade de vida varia de acordo com o EHIS avaliado. Em reassentamentos, por exemplo, a melhoria da qualidade de vida pode estar mais vinculada a questões de habitabilidade, enquanto em empreendimentos cujos beneficiários antes alugavam uma moradia pode estar relacionado a novas possibilidades de investimento familiar, como em lazer ou educação. Caso fosse realizada uma avaliação com enfoque nos moradores do entorno ou da cidade, por exemplo, outros objetivos poderiam ser identificados, tais como reestruturação urbana, entre outros. Assim, é necessária uma revisão desse objetivo a cada EHIS avaliado, uma vez que podem ocorrer mudanças e emergirem outros objetivos.

\section{Conjunto de constructos para avaliação}

Os constructos identificados neste estudo foram categorizados segundo as partes do produto EHIS e, posteriormente, traduzidos em itens de avaliação com o auxílio das pesquisas anteriores. Parte-se do princípio de que, a partir da identificação do escopo do produto, podem ser extraídos do conjunto os constructos e itens de avaliação de acordo com as consequências esperadas para o EHIS em questão, complementando-se com outros constructos, ou itens de avaliação, quando necessário. Assim, a proposta não foi esgotar as possibilidades em relação ao que deveria ser avaliado. Ao contrário, o conjunto de constructos pode ser complementado a cada avaliação realizada. O Quadro 2 apresenta um exemplo do conjunto de constructos genéricos para avaliação do entorno dos empreendimentos.

\begin{tabular}{|c|c|c|c|}
\hline & & $\begin{array}{l}\text { CONSEQUÊNCIAS } \\
\text { DE USO }\end{array}$ & ITENS PARA AVALIAÇÃO DA SATISFAÇÃO \\
\hline \multirow{7}{*}{ 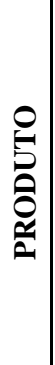 } & \multirow{7}{*}{ 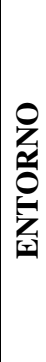 } & SEGURANÇA & a) Segurança nos arredores do condomínio \\
\hline & & LOCALIZAÇÃO & a) Localização no seu condomínio/loteamento \\
\hline & & \multirow{5}{*}{$\begin{array}{c}\text { ACESSIBILIDADE A } \\
\text { TRANSPORTE E } \\
\text { EQUIPAMENTOS } \\
\text { URBANOS }\end{array}$} & $\begin{array}{l}\text { a) Facilidade de acesso ao condomínio/loteamento por } \\
\text { transporte coletivo }\end{array}$ \\
\hline & & & b) Proximidade de áreas de comércio \\
\hline & & & c) Proximidade de áreas para o lazer e a prática de esportes \\
\hline & & & d) Proximidade de creches e escolas \\
\hline & & & e) Facilidade de acesso a posto de saúde e/ou hospital \\
\hline
\end{tabular}

Quadro 2 - Exemplo do conjunto de constructos para avaliação do entorno 


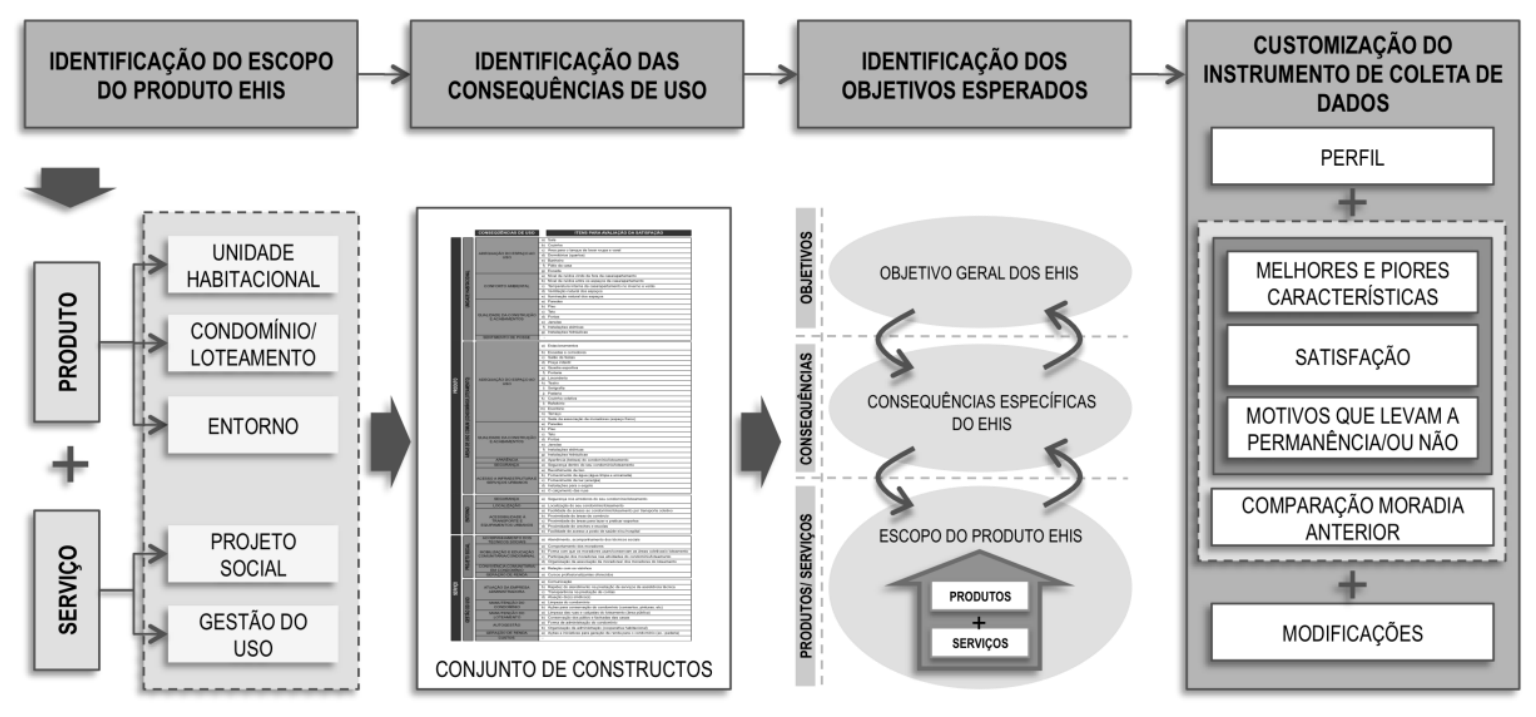

Figura 2 - Preparação da avaliação de EHIS

\section{Instrumento de coleta de dados}

Com base em questionários utilizados em pesquisas anteriores (TZORTZOPOULOS et al., 2000; MIRON, 2002, 2008; LEITE, 2005), o instrumento proposto para a coleta de dados na pesquisa consiste em um questionário composto de oito seções: ${ }^{6}$
(a) identificação;
(b) perfil do cliente final;
(c) melhores e piores características;
(d) satisfação com o produto;
(e) satisfação com o serviço;
(f) modificações;
(g) comparação com a moradia anterior; e
(h) intenção de permanência.

Essas seções devem ser customizadas de acordo com o empreendimento avaliado.

\section{Processo de avaliação}

Para a aplicação do modelo de avaliação foi proposto um roteiro, dividido em três etapas:
(a) preparação da avaliação;
(b) implementação da avaliação; e
(c) discussão e disseminação dos resultados.

\footnotetext{
${ }^{6}$ A Metodologia de pesquisa foi proposta com base no questionário desenvolvido por Miron (2008). Em Resultados e discussão e Conclusões, que visam à avaliação da satisfação, tiveram por base o questionário proposto por Tzortzopoulos et al. (2000) e refinado por Miron $(2002,2008)$ e Leite (2005).
}

\section{Preparação da avaliação}

A primeira etapa do processo de avaliação consiste na identificação do escopo do EHIS, consequências e objetivos esperados e customização do instrumento de coleta de dados, como é apresentado na Figura 2. A fase de preparação da avaliação é muito importante, uma vez que, nesta pesquisa, foi entendido que definir um padrão estático de avaliação não refletiria as singularidades dos EHIS, gerando resultados pouco conectados com os seus objetivos.

Para identificação do escopo do produto, das consequências e dos objetivos esperados são necessárias informações sobre o EHIS, inclusive sobre o período de uso até a avaliação, e sobre o programa habitacional em que foi desenvolvido. Tais informações podem ser buscadas em documentos sobre o empreendimento e diretamente com os envolvidos no seu processo de desenvolvimento. Preferencialmente, para essas identificações, bem como para a customização do instrumento de coleta, sugere-se a realização de uma reunião com a equipe multidisciplinar que participou do processo de desenvolvimento. Para tanto, a coluna relativa a consequências de uso do conjunto de constructos serve como base para as discussões. Desse conjunto são extraídos os constructos e itens de avaliação, podendo ser complementado, caso necessário.

Nessa etapa da avaliação, o modelo conceitual (Figura 1) é utilizado de forma exploratória, identificando os produtos e serviços que compõem o EHIS e as consequências esperadas, em diferentes níveis de abstração. Essa hierarquia deve ser utilizada na reunião para definição da avaliação, explicitando as informações. 
Por fim, após a definição da avaliação, nessa etapa são realizados o planejamento amostral e de coleta de dados. Um aspecto relevante na customização do instrumento de coleta de dados é o tamanho dele, o que pode ser verificado pelo tempo de aplicação em um pré-teste. Também é de fundamental importância $\mathrm{o}$ treinamento dos entrevistadores que irão realizar a coleta.

\section{Implementação da avaliação}

$\mathrm{Na}$ segunda etapa ocorre a coleta de dados no EHIS e o seu processamento. A realização dessas atividades pode ser a cargo do agente responsável pela execução do TTS, uma vez que essa avaliação pode ser entendida como a que consta no Caderno de Orientação Técnico Social (CAIXA, 2009).

No processamento das avaliações é também utilizado o modelo conceitual (Figura 1). Nesta etapa, a hierarquia reflete os resultados das melhores e piores características, da avaliação de satisfação e dos motivos para permanecer ou não no EHIS. A partir das respostas qualitativas buscase identificar relações entre as partes do produto e as consequências de uso, bem como entre consequências em diferentes níveis e entre consequências e objetivos, de forma a verificar influências e melhor entender os resultados. Ainda, os resultados dessa etapa podem ser comparados à hierarquia desenvolvida na etapa anterior, possibilitando aprendizagem acerca de novos constructos evidenciados na avaliação e nas relações existentes.

\section{Discussão e disseminação dos resultados}

Nesta etapa da pesquisa é importante que haja discussão acerca dos resultados, que podem ser realizadas a partir de apresentações. As informações geradas no processo de avaliação devem ser analisadas pelos envolvidos no processo de desenvolvimento de EHIS e disseminadas a fim de possibilitar sua utilização. Por influenciarem distintos aspectos dos EHIS, é importante que a disseminação atinja a todos os envolvidos, principalmente no que tange aos agentes responsáveis pela operação e gestão dos programas habitacionais e pelo desenvolvimento dos empreendimentos.

\begin{tabular}{|c|c|c|c|}
\hline & Estudo 1 & Estudo 2 & Estudo 3 \\
\hline \multicolumn{4}{|l|}{ ETAPA } \\
\hline $\begin{array}{l}\text { Preparação da } \\
\text { avaliação }\end{array}$ & $\begin{array}{c}\text { Reunião com } 1 \text { técnica social } \\
\text { da CAIXA e entrevista com } 1 \\
\text { dos líderes comunitários para } \\
\text { obtenção de informações } \\
\text { Montagem da avaliação pela } \\
\text { pesquisadora }\end{array}$ & $\begin{array}{l}\text { Reunião com } 1 \text { técnica social } \\
\text { da CAIXA para obtenção de } \\
\text { informações } \\
\text { Montagem da avaliação pela } \\
\text { pesquisadora }\end{array}$ & $\begin{array}{c}\text { Montagem da avaliação em } \\
\text { uma reunião com } 2 \text { técnicas } \\
\text { sociais da CAIXA e equipe } \\
\text { multidisciplinar de Novo } \\
\text { Hamburgo ( } 2 \text { assistentes } \\
\text { sociais, } 1 \text { engenheiro e } 1 \\
\text { psicopedagoga) }\end{array}$ \\
\hline $\begin{array}{l}\text { Implementação } \\
\text { da avaliação }\end{array}$ & $\begin{array}{c}\text { Coleta de dados realizada por } 2 \\
\text { pesquisadoras do NORIE } \\
\text { Tempo de coleta: } 2 \text { dias ( } 27 \\
\text { questionários) } \\
\text { Processamento por } \\
\text { pesquisadores NORIE }\end{array}$ & $\begin{array}{c}\text { Coleta de dados realizada por } 5 \\
\text { pesquisadores do NORIE } \\
\text { Tempo de coleta: } 1 \text { dia ( } 80 \\
\text { questionários) } \\
\text { Processamento por } \\
\text { pesquisadores NORIE }\end{array}$ & $\begin{array}{c}\text { Coleta de dados realizada pela } \\
\text { pesquisadora e } 3 \text { assistentes } \\
\text { sociais de empresas contratadas } \\
\text { pela CAIXA } \\
\text { Treinamento mais elaborado } \\
\text { (recursos visuais) } \\
\text { Tempo de coleta: } 2 \text { dias ( } 67 \\
\text { questionários) } \\
\text { Processamento por } \\
\text { pesquisadores NORIE }\end{array}$ \\
\hline $\begin{array}{c}\text { Discussão e } \\
\text { disseminação } \\
\text { dos resultados }\end{array}$ & \multicolumn{2}{|c|}{$\begin{array}{l}\text { Apresentação e discussão dos resultados com } 3 \text { técnicas sociais da } \\
\text { CAIXA }\end{array}$} & $\begin{array}{c}\text { Apresentação e discussão dos } \\
\text { resultados com } 4 \text { profissionais } \\
\text { da Prefeitura de Novo } \\
\text { Hamburgo e } 3 \text { técnicas sociais } \\
\text { da CAIXA }\end{array}$ \\
\hline \multicolumn{4}{|c|}{ DURAÇÃO APROXIMADA } \\
\hline $\begin{array}{l}\text { Duração da } \\
\text { avaliação }\end{array}$ & Mais de um mês & Cerca de duas semanas & Cerca de uma semana \\
\hline
\end{tabular}

Quadro 3 - Resumo do processo de avaliação nos três estudos 


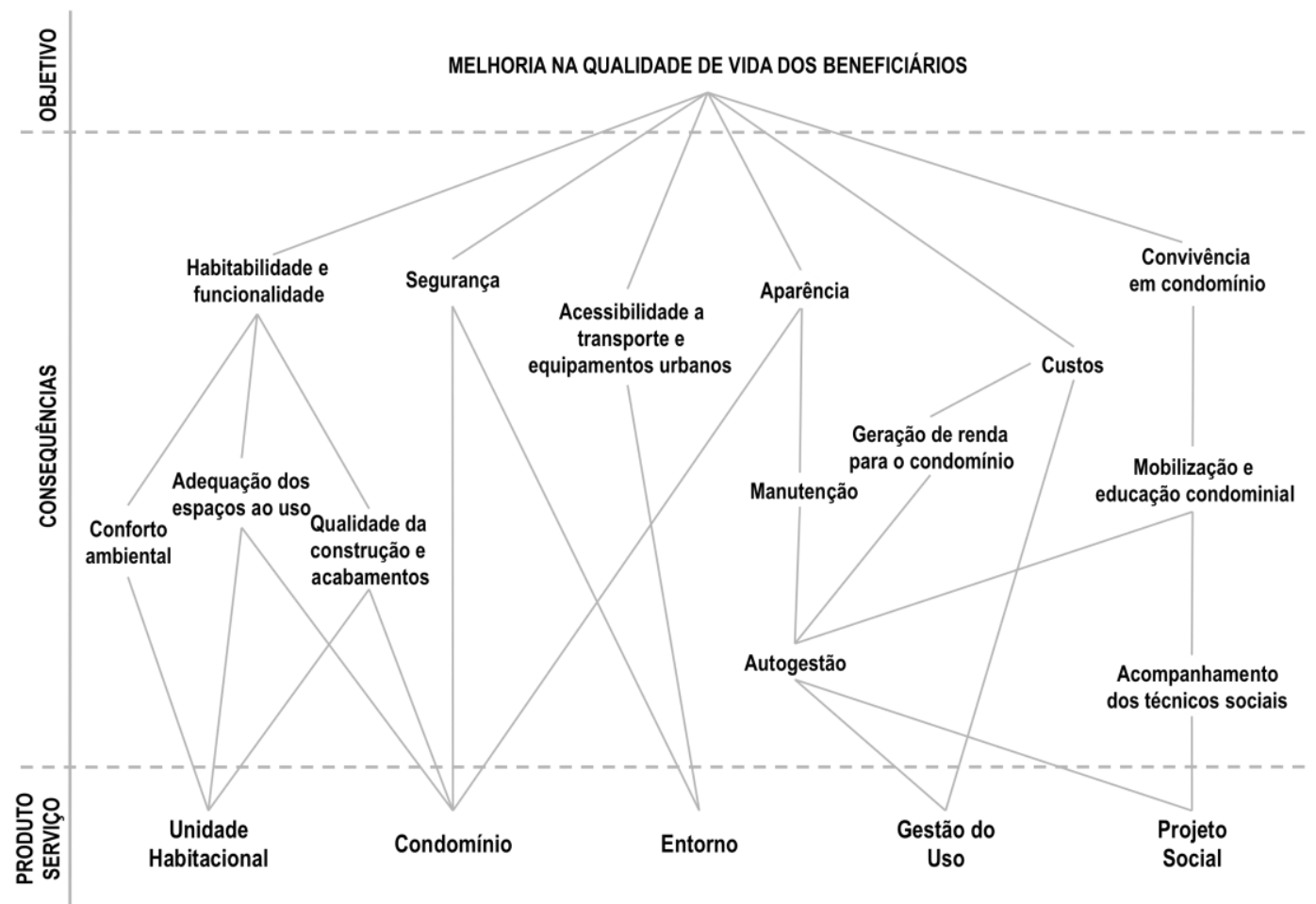

Figura 3 - Exemplo da hierarquia resultante na etapa de montagem da avaliação do Estudo 1

\section{Aplicação da avaliação}

O Quadro 3 apresenta resumidamente como foi realizado o processo de avaliação nos três estudos realizados. É possível perceber que, no decorrer dos estudos, houve diminuição no tempo de desenvolvimento das avaliações. Isso foi devido à diminuição de retrabalho e à maior definição quanto ao modelo de avaliação, uma vez que ele foi aprimorado no processo. O processo dos dois primeiros estudos foi bastante semelhante. Já no Estudo 3 houve maior envolvimento dos técnicos da CAIXA. As principais diferenças são nas etapas de preparação e implementação da avaliação, destacando-se a montagem da hierarquia com o que era esperado para o empreendimento, como no exemplo da Figura 3, e customização do instrumento de coleta.

Com relação aos resultados das avaliações, um resumo com maiores percentuais é apresentado na Tabela 1. Ainda, como principal produto das avaliações, os resultados referentes às melhores $\mathrm{e}$ piores características, satisfação e motivos para permanecer ou não no imóvel são mostrados de forma integrada, sendo a Figura 4, a Figura 5 e a Figura 6 referentes aos Estudos 1, 2 e 3 respectivamente. Nessas figuras buscou-se salientar os constructos e as relações identificadas a partir dos resultados. Essas relações e constructos emergiram, principalmente, a partir das observações e citações qualitativas do questionário.

Analisando os resultados, sobretudo nos dois primeiros estudos, aspectos relacionados à gestão do uso e ao projeto social parecem ser potenciais influenciadores das percepções dos usuários. No Estudo 1, as citações enfatizaram a organização e a participação dos moradores, bem como a autonomia do empreendimento, enquanto no Estudo 2 foram citadas considerações sobre a falta de organização, de cuidado dos moradores no uso de áreas coletivas e de autonomia. Em ambos os casos, as influências parecem ter afetado percepções de outros aspectos do empreendimento, sendo no primeiro de forma positiva e no segundo de forma negativa.

Os resultados positivos da avaliação do EHIS 1 podem ser explicados, com base em Sanoff (2008), pela participação dos moradores. Segundo esse autor, parte-se do princípio de que o ambiente funciona melhor se os cidadãos são ativos e envolvidos na sua criação e gestão, em vez de serem apenas consumidores passivos. Neste empreendimento, a maioria dos moradores não participou da criação, mas participa da gestão (autogestão). Ainda, no EHIS 1 a participação dos moradores também atinge o projeto social, relacionando-o com a autogestão. 
Tabela 1 - Tabela-resumo dos principais resultados das avaliações realizadas nos três estudos

EHIS 1 EHIS 2 EHIS 3

PERFIL

\begin{tabular}{|c|c|c|c|}
\hline $\begin{array}{l}\text { Agrupamento } \\
\text { domiciliar }\end{array}$ & Pessoa sozinha (39\%) & Casal com filhos (37\%) & Casal com filhos $(58 \%)$ \\
\hline $\begin{array}{l}\text { Escolaridade do } \\
\text { responsável }\end{array}$ & $\begin{array}{l}\text { Ensino médio completo }(29 \%) \\
\text { Ensino superior incompleto } \\
(29 \%)\end{array}$ & Ensino médio completo (43\%) & De $5^{\mathrm{a}}$ a $8^{\mathrm{a}}$ série incompleta $(33 \%)$ \\
\hline Moradia anterior & Alugada (43\%) & Alugada (49\%) & Área irregular/ própria (77\%) \\
\hline \multicolumn{4}{|c|}{ MELHORES E PIORES CARACTERÍSTICAS } \\
\hline \% citações & Positivas $(61 \%)$ & Negativas $(63 \%)$ & Positivas $(63 \%)$ \\
\hline $\begin{array}{l}\text { Melhores } \\
\text { características }\end{array}$ & $\begin{array}{l}\text { Convivência em condomínio } \\
(14,7 \%) \\
\text { Localização }(14,7 \%)\end{array}$ & $\begin{array}{l}\text { Acessibilidade a transporte e } \\
\text { equipamentos urbanos }(20 \%)\end{array}$ & $\begin{array}{l}\text { Acesso a infraestrutura e a } \\
\text { serviços urbanos }(23,7 \%)\end{array}$ \\
\hline $\begin{array}{l}\text { Piores } \\
\text { características }\end{array}$ & Conforto ambiental (40\%) & $\begin{array}{l}\text { Acessibilidade a transporte e } \\
\text { equipamentos urbanos }(13,8 \%)\end{array}$ & Localização $(12,1 \%)$ \\
\hline \multicolumn{4}{|l|}{ SATISFAÇÃO } \\
\hline Maior satisfação & $\begin{array}{l}\text { Aparência do condomínio (96\%) } \\
\text { Comportamento dos moradores } \\
(96 \%)\end{array}$ & Iluminação natural (80\%) & Recolhimento do lixo (96\%) \\
\hline $\begin{array}{l}\text { Maior } \\
\text { insatisfação }\end{array}$ & Segurança no entorno $(82 \%)$ & $\begin{array}{l}\text { Adequação da área de serviço } \\
(81 \%)\end{array}$ & $\begin{array}{l}\text { Proximidade de áreas para lazer e } \\
\text { esportes }(69 \%)\end{array}$ \\
\hline \multicolumn{4}{|c|}{ MOTIVOS PARA PERMANECER OU NÃO NO IMÓVEL } \\
\hline \% intenção & Permanecer $(95 \%)$ & Não permanecer $(65 \%)$ & Permanecer $(89 \%)$ \\
\hline $\begin{array}{l}\text { Motivo para } \\
\text { permanecer }\end{array}$ & Sentimento de posse $(28,6 \%)$ & Sentimento de posse $(42,4 \%)$ & Sentimento de posse (34\%) \\
\hline $\begin{array}{l}\text { Motivo para não } \\
\text { permanecer }\end{array}$ & $\begin{array}{l}\text { Adequação ao uso dos espaços } \\
(100 \%)\end{array}$ & $\begin{array}{l}\text { Adequação ao uso dos espaços } \\
(22,1 \%)\end{array}$ & $\begin{array}{l}\text { Adequação ao uso dos espaços } \\
(28,6 \%) \\
\text { Localização }(28,6 \%)\end{array}$ \\
\hline \multicolumn{4}{|c|}{ COMPARAÇÃO COM A MORADIA ANTERIOR } \\
\hline $\begin{array}{l}\text { Habitabilidade e } \\
\text { funcionalidade }\end{array}$ & Impacto positivo (57\%) & Impacto positivo (47\%) & Impacto positivo (83\%) \\
\hline Localização & Impacto positivo (98\%) & Impacto negativo (43\%) & Impacto positivo (86\%) \\
\hline Aparência & Impacto positivo $(68 \%)$ & $\begin{array}{l}\text { Impacto positivo (36\%) } \\
\text { Impacto negativo }(36 \%)\end{array}$ & Impacto positivo (89\%) \\
\hline Segurança & $\begin{array}{l}\text { Impacto positivo }(46 \%) \\
\text { Neutro }(46 \%)\end{array}$ & Impacto negativo (37\%) & Impacto positivo $(75 \%)$ \\
\hline Convivência & Impacto positivo $(75 \%)$ & Neutro $(58 \%)$ & Impacto positivo $(65 \%)$ \\
\hline $\begin{array}{l}\text { Infraestrutura e } \\
\text { serviços urbanos }\end{array}$ & - & - & Impacto positivo (87\%) \\
\hline \multicolumn{4}{|c|}{ MELHORIAS REALIZADAS E PRETENDIDAS } \\
\hline \% modificação & $68 \%$ & $90 \%$ & $87 \%$ \\
\hline $\begin{array}{l}\text { Melhorias } \\
\text { realizadas }\end{array}$ & Revestimento horizontal (57\%) & Revestimento horizontal (99\%) & Revestimento horizontal (76\%) \\
\hline \% pretensão & $86 \%$ & $68 \%$ & $96 \%$ \\
\hline $\begin{array}{l}\text { Melhorias } \\
\text { Pretendidas }\end{array}$ & Revestimento vertical (36\%) & Revestimento vertical (52\%) & Ampliação (76\%) \\
\hline
\end{tabular}



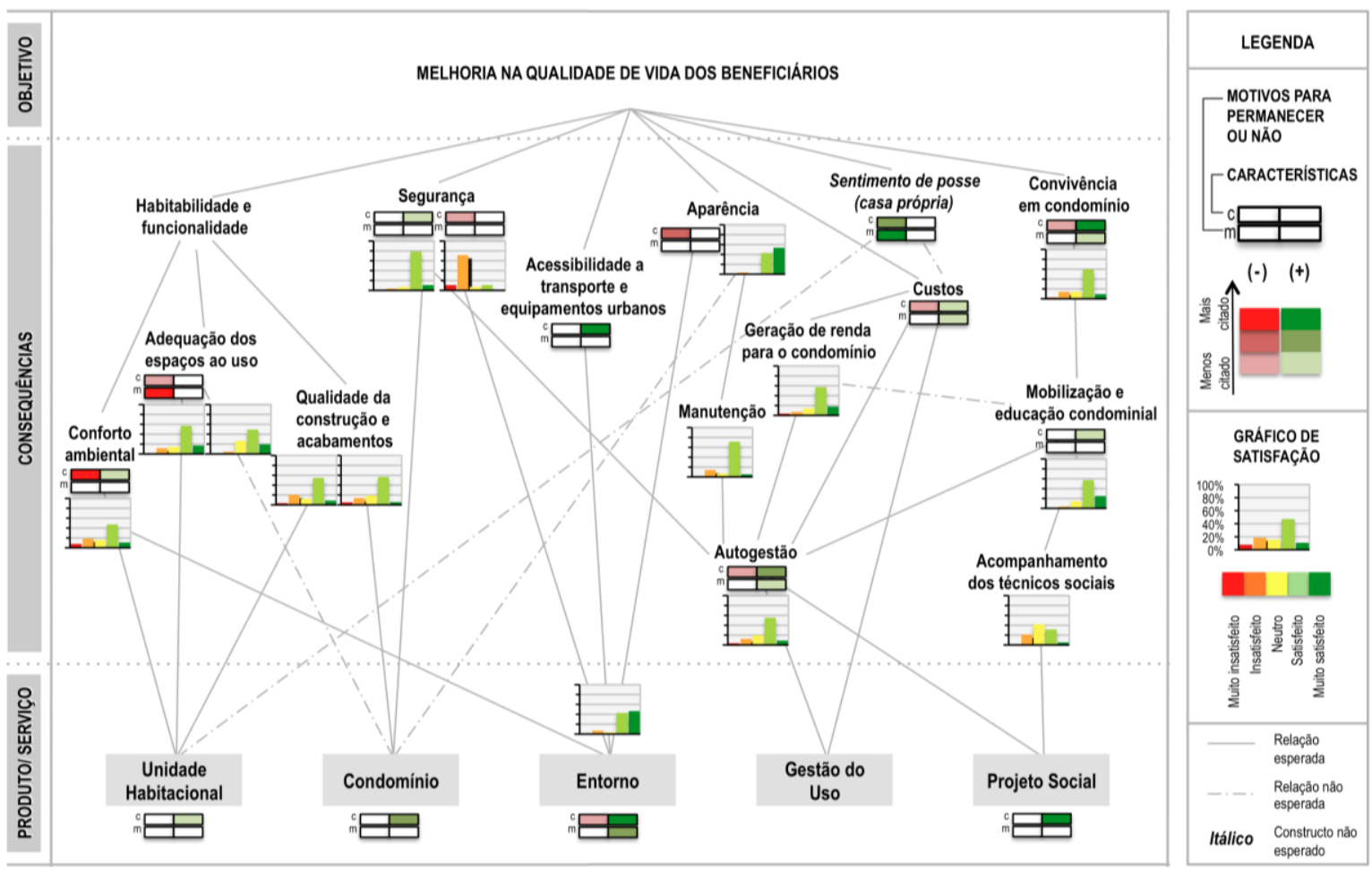

Figura 4 - Resultado geral da avaliação EHIS 1
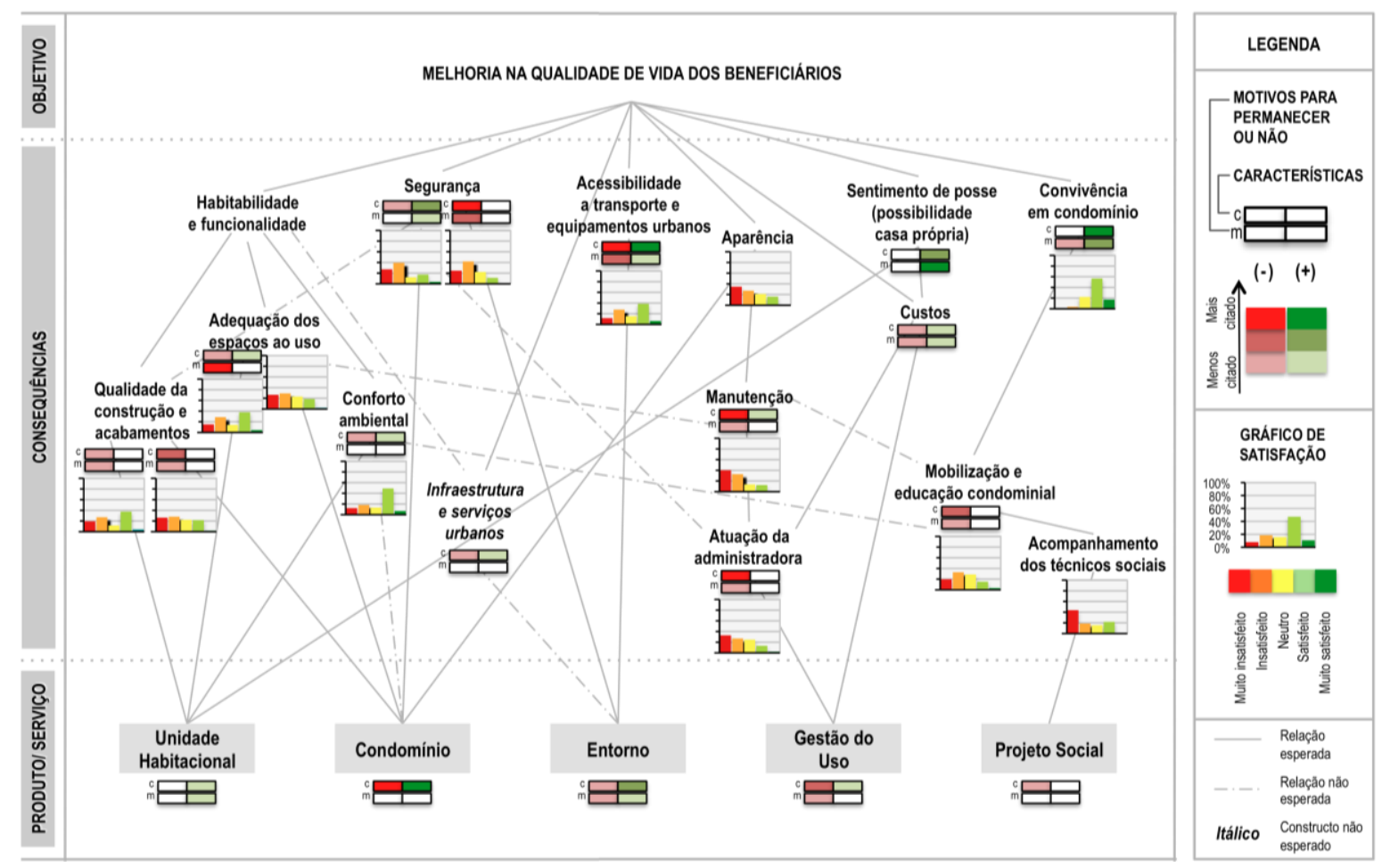

Figura 5 - Resultado geral da avaliação EHIS 2 

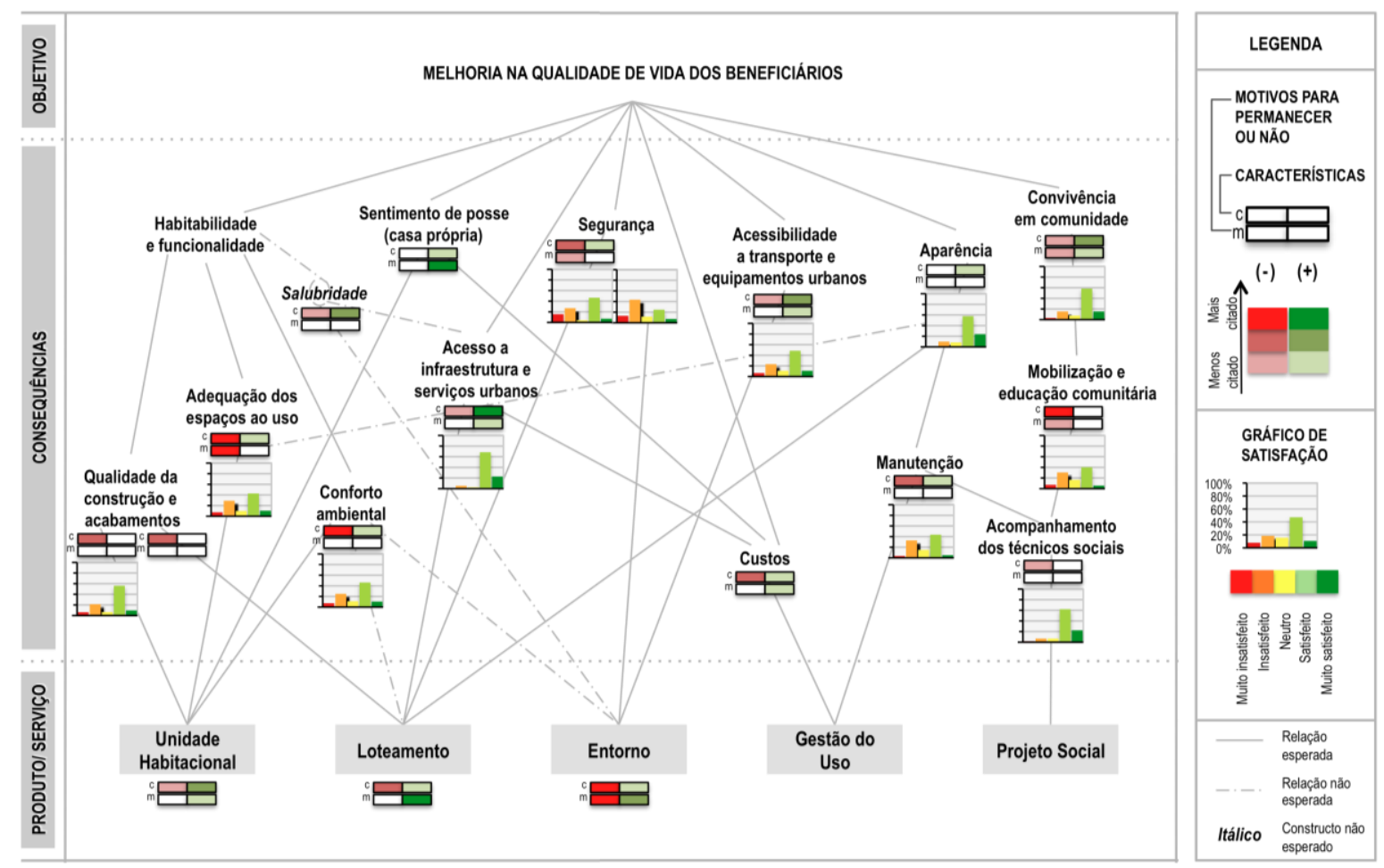

Figura 6 - Resultado geral da avaliação EHIS 3

No que se refere às características, por diversas vezes houve citações positivas e negativas referentes a uma mesma parte do produto. De forma geral, foi observado que as características positivas muitas vezes eram mencionadas em termos de atributos do produto (por exemplo, ter portaria), enquanto as negativas refletiam problemas sobre o produto em uso (por exemplo, a portaria não funciona).

As principais citações sobre as melhores e piores características variaram conforme o empreendimento avaliado, diferentemente dos motivos para permanecer, ou não, no imóvel, conforme pode ser observado na Tabela 1 . Nos três estudos, o sentimento de posse foi o principal motivo para permanecer, enquanto a inadequação do espaço da unidade habitacional foi o principal dos motivos para não querer permanecer no empreendimento. Uma consideração que pode ser feita é que talvez a aquisição da casa própria seja o principal objetivo na perspectiva dos usuários, diferente do ponto de vista do agentes responsáveis pela operação e gestão dos programas habitacionais, que têm como objetivo final do desenvolvimento de EHIS a melhoria da qualidade de vida dos beneficiários.

No entanto, foi possível traçar relações entre o sentimento de posse e a melhoria da qualidade de vida esperada. Segundo Araujo (2008), a casa própria é um objeto de desejo que inclui o indivíduo e que altera o seu status na sociedade.
Além disso, a casa própria foi citada nos estudos como uma estabilidade, gerando segurança por ser legalizada, sendo relacionada também à redução de custos com aluguel, o que possibilitava outros investimentos, como em educação. No EHIS 3, um outro benefício citado como derivado da legalidade da propriedade era a possibilidade de realizar reformas e ampliações, customizando a casa conforme necessário. Cabe salientar que, no EHIS 2, a propriedade do imóvel só ocorre após o período de aluguel social, que pode perdurar até 15 anos.

Já em relação aos motivos para a não permanência, a inadequação da unidade habitacional foi citada como a necessidade de mais espaço. No EHIS 3, apesar de a tipologia casa possibilitar ampliação, diferentemente do que ocorre em empreendimentos verticais, como no EHIS 1 e no EHIS 2, e do terreno disponível para tanto, as condições financeiras nem sempre comportavam esse tipo de reforma. Para essa situação de dificuldade, alguns moradores do EHIS 3 apontaram como uma solução a troca dessa unidade por outra mais simples, mas de maior tamanho. Essa troca ou venda foi identificada como já realizada em algumas unidades, e os atuais moradores, por vezes, também explicavam a referida situação.

Algo que deve ser ressaltado acerca dos resultados dos empreendimentos é o tempo de moradia. O EHIS 1 e o EHIS 3 foram avaliados quando os 
moradores estavam há pouco menos de 1 ano no empreendimento, enquanto no EHIS 2 o tempo de ocupação era cerca de 4 anos. Woodruff (1997) afirma que a satisfação é o sentimento do cliente em resposta às avaliações de uma ou mais experiências de uso de determinado produto. Assim, é destacável que a experiência de consumo no EHIS 2 é maior do que nos outros empreendimentos, o que pode suscitar em mais experiências positivas ou negativas acumuladas.

Outro fato que deve ser considerado é a diferença de perfil e de necessidades e expectativas dos moradores quanto ao EHIS. Como apresentado, apesar dessas diferenças, houve semelhança em alguns dos resultados, mas outros mostraram diferenças evidentes, conforme já era esperado. No EHIS 3, por exemplo, as melhores características citadas estão relacionadas com o acesso a infraestrutura e serviços urbanos e seus benefícios quanto à salubridade. Tais aspectos não aparecem no EHIS 1 e pouco aparecem no EHIS 2, provavelmente por serem considerados pelos moradores desses empreendimentos como requisitos básicos e já atendidos na moradia anterior. Nestes dois empreendimentos, justamente devido às diferenças quanto aos objetivos dos EHIS, o acesso a infraestrutura e serviços urbanos não era considerado um benefício esperado para a melhoria da habitabilidade.

Esse fato corrobora as diferenças entre consequências esperadas, e também percebidas, para empreendimentos de distintos programas, denotando a necessidade de que a avaliação realmente considere tais aspectos. No decorrer da pesquisa foi evidenciado que a hierarquia de valor é específica de cada EHIS proposto. Mesmo empreendimentos que apresentem escopo, consequências e objetivo similares, podem apresentar diferentes relações nas avaliações.

Ainda com relação às consequências, na montagem da avaliação é identificado o que era esperado com o produto EHIS, ou seja, a partir de quais aspectos estava se buscando a melhoria da qualidade de vida dos beneficiários em cada empreendimento. Essa explicitação é referente ao valor esperado pelos agentes que desenvolveram o produto, o que acaba sendo uma contribuição na utilização do modelo, já que muitas vezes não é deixado claro no processo. Já a partir dos resultados é possível identificar quais são as percepções dos usuários sobre as consequências, bem como as suas influências no alcance do objetivo esperado. Os resultados das avaliações podem ser explicados como a comparação entre o valor desejado e o recebido pelo usuário (WOODRUFF; GARDIAL, 1996), que pode conduzir à satisfação, ou não, em cada nível da hierarquia (WOODRUFF, 1997).

Por fim, ao analisar os resultados de diferentes fontes de evidência de forma conjunta e comparar a hierarquia do valor esperado pelos agentes com a do valor percebido pelos usuários, é possível identificar quais são os benefícios previstos que estão sendo realmente atingidos. Essa comparação também pode auxiliar na aproximação entre as esferas de desenvolvimento e consumo dos EHIS.

\section{Conclusões}

A presente pesquisa utilizou a hierarquia de valor proposta por Gutman (1982) e Woodruff e Gardial (1996) como base conceitual para o desenvolvimento de avaliações de empreendimentos em uso, considerando a percepção de usuários. O modelo desenvolvido, como indicado por esses autores, apresenta três níveis de abstração, referentes ao escopo do produto EHIS, suas consequências específicas e objetivos. A partir dessa perspectiva hierárquica foi possível contribuir para que a avaliação não focasse apenas em atributos do produto, possibilitando uma aprendizagem sobre a relevância de cada uma das suas partes mediante as suas vinculações com consequências e objetivos.

Para o desenvolvimento do modelo, a partir de estudos sobre os programas habitacionais existentes e os empreendimentos resultantes, foi mapeado o produto EHIS. Por meio desses estudos foi possível perceber que o produto EHIS não é tão variável quanto os programas habitacionais.

A fim de operacionalizar o modelo proposto identificou-se um conjunto de constructos que podem ser usados para explicar o valor percebido na perspectiva dos usuários sobre os EHIS. Desse conjunto são extraídas as consequências de uso esperadas para o empreendimento a ser avaliado, complementando-o caso necessário. Foi desenvolvido, também, um instrumento de coleta de dados, que deve ser customizado conforme a avaliação.

Ainda, propôs-se um roteiro de aplicação do modelo de avaliação. Na proposta da pesquisa, a estrutura hierárquica do modelo é utilizada na preparação da avaliação e para a análise dos resultados. Na preparação da avaliação, a hierarquia é inicialmente montada de acordo com o que é esperado pelos agentes envolvidos no processo de desenvolvimento do empreendimento, com base na sua perspectiva de valor esperado sobre o que gera valor para o usuário final. Essa explicitação é uma das contribuições da pesquisa, uma vez que objetivos esperados geralmente não 
são claros nesse tipo de empreendimento. Durante a execução da avaliação os usuários são questionados acerca das consequências de uso esperadas e há a possibilidade de emergir novos constructos e relações a partir da perspectiva de valor recebido deles. A partir dos resultados da avaliação, uma nova hierarquia é montada, possibilitando comparações entre as perspectivas de agentes e usuários e aproximando essas duas esferas.

Contribuindo para o desenvolvimento do modelo, foram realizados três estudos, nos quais foram avaliados EHIS de diferentes programas e com características peculiares. Ao estudar quais eram os benefícios esperados para os EHIS, constatou-se que existem variações entre hierarquias de valor esperado para programas e entre empreendimentos de um mesmo programa. Nesse sentido, foi possível perceber que o modelo se adaptou às diversidades, mostrando as particularidades de cada empreendimento.

Por fim, cabe salientar que nos estudos, bem como no desenvolvimento do modelo de avaliação, houve a participação de técnicos sociais da CAIXA. Essa participação trouxe várias contribuições. Uma delas é a aproximação entre os resultados da pesquisa acadêmica com os agentes responsáveis pela tomada de decisão na concepção e desenvolvimento de empreendimentos e programas.

\section{Referências}

ANDERSON, J. C.; JAM, D. C.; CHINTAGUNTA, P. K. Customer Value Assessment in Business Markets: A State-ofPractice Study. Journal of Business-to-Business Marketing, Pennsylvania, v. 1, n. 1, 1993.

ARAUJO, A. C. S. A Casa [Própria] Alugada: questões da política pública habitacional. Risco: Revista de Pesquisa em Arquitetura e Urbanismo, São Carlos,v. 7, p. 165-176, 2008.

BARLOW, J.; OZAKI, R. Achieving 'Customer Focus' in Private Housebuilding: Current Practice and Lessons from Other Industries. Housing Studies, v. 18, n. 1, p. 87-101, ago. 2003.

BORDASS, B. Learning More from Our Buildings: or just forgetting less? Building Research \& Information, v. 31, n. 5, p. 406-411, 2003.

BORDASS, B.; LEAMAN, A. Phase 5: occupancy, post-occupancy evaluation. In: PREISER, W. F. E.; VISCHER, J. C. (Eds.). Assessing Building Performance. [ S.1.]: Elsevier, 2005.
BONATTO, S. F. Proposta de um Modelo para Avaliação de Empreendimentos Habitacionais de Interesse Social a Partir da Percepção de Clientes Finais. 2010. 178 f. Dissertação (Mestrado em Engenharia Civil) - Escola de Engenharia, Universidade Federal do Rio Grande do Sul, Porto Alegre, 2011.

CAIXA ECONÔMICA FEDERAL. Caderno de Orientação Técnico Social - COTS. [S.1.]: Caixa Econômica Federal, 2009. Disponível em: <http://www1.caixa.gov.br/download/index.asp>. Acesso em: 5 set. 2009.

EGGERT, A.; ULAGA, W. Customer Perceived Value: a substitute for satisfaction in business markets? Journal of Business \& Industrial Marketing, v. 17, n. 2/3, p. 107-118, 2002.

GANN, D.; SALTER, A.; WHYTE, J. Design Quality Indicator as a Tool for Thinking. Building Research \& Information, v. 31, n. 5, p. 318-333, 2003.

GRANJA, A. D. Et al. A Natureza do Valor Desejado na Habitação Social. Ambiente Construído, Porto Alegre, v. 9, n. 2, p. 87-103, abr./jun. 2009.

GUTMAN, J. A Means-End Chain Model Based on Consumer Categorization Processes. Journal of Marketing, v. 46, n. 2, p. 60-72, primavera 1982.

HOLBROOK, M. B. Consumption Experience, Customer Value, and Subjective Personal Iintrospection: an illustrative photographic essay. Journal of Business Research, v. 59, n. 6, p. 714 725, 2006.

INSTITUTO DE PESQUISA ECONÔMICA APLICADA. Habitação. In: IPEA. Políticas Sociais: acompanhamento e análise, v. 14, p. 279302, fev. 2007

KOSKELA, L. An Exploration Towards a Production Theory and its Application to Construction. 2000, 296 f. These (Doutorado em Tecnologia) - VTT Technical Research Centre of Finland, Helsinki, 2000.

LEINONEN, J.; HUOVILA, P. Requirements Management in Life-Cycle Design. Finland: VTT Building Technology, 2000.

LEITE, F. L. Contribuições para o Gerenciamento de Requisitos do Cliente em Empreendimentos do Programa de Arrendamento Residencial. 2005. 179 f. Dissertação (Mestrado em Engenharia Civil) Escola de Engenharia, Universidade Federal do Rio Grande do Sul, Porto Alegre, 2005. 
LIMA, L. P. Proposta de uma Sistemática para o Processamento de Requisitos do Cliente de Empreendimentos Habitacionais de Interesse Social. 2007. 190 f. Dissertação (Mestrado em Engenharia Civil) - Programa de Pós-Graduação em Engenharia Civil, Universidade Federal do Rio Grande do Sul, Porto Alegre, 2007.

LOVELOCK, C.; WRIGHT, L. Principles of Service Marketing and Management. New Jersey: Prentice Hall, 2002.

LUKKA, K. The Constructive Research Approach. In: OJALA, L.; HILMOLA, O.-P. (Eds.). Case Study Research in Logistics. Turku: Turku School of Economics and Business Administration, 2003. Series B1. p. 83-101.

MILLER, C.; SWADDLING, D. C. Focusing NPD Research on Customer-Perceived Value. In: BELLIVEAU, P.; GRIFFIN, A.; SOMERMEYER, S. The PDMA Toolbook for New Product Development. [N.1.]: John Wiley and Sons, 2002. Cap. 4, p. 87-114.

MIRON, L. Proposta de Diretrizes para o Gerenciamento dos Requisitos do Cliente em Empreendimentos da Construção. 2002. 150 f. Dissertação (Mestrado em Engenharia Civil) Escola de Engenharia, Universidade Federal do Rio Grande do Sul, Porto Alegre, 2002.

MIRON, L. Gerenciamento dos Requisitos dos Clientes de Empreendimentos Habitacionais de Interesse Social: proposta para o Programa Integrado Entrada da Cidade em Porto Alegre/RS. 2008. 350 f. Tese (Doutorado em Engenharia Civil) - Escola de Engenharia, Universidade Federal do Rio Grande do Sul, Porto Alegre, 2008.

MONROE, Kent B. Pricing: making profitable decisions. New York: McGraw-Hill, 1990. 502 p.

MORAES, O. B.; ABIKO, A. K. Considerações Sobre a Utilização de Medidas de Incerteza em Dados de Percepção do Morador. In: ENCONTRO NACIONAL DE TECNOLOGIA DO AMBIENTE CONSTRUÍDO, 11., 2006, Florianópolis. Anais... Florianópolis: ANTAC, 2006. p. 1243-1252.

ORNSTEIN, S. W.; CRUZ, A. O. Análise de Desempenho Funcional de Habitações de Interesse Social na Grande São Paulo. In: ENCONTRO NACIONAL DE TECNOLOGIA DO AMBIENTE CONSTRUÍDO, 8., 2000, Salvador. Anais... Salvador: ANTAC, 2000. v. 2, p.14391446.

PINHEIRO, R. M. et al. Comportamento do Consumidor e a Pesquisa de Mercado. 2. ed. Rio de Janeiro: FGV, 2005. 164 p.
RAVALD, A.; GRÖNROOS, C. The Value Concept and Relationship Marketing. European Journal of Marketing, v. 30, n. 2, p. 19-32, 1996.

ROMERO, M. A.; VIANNA, N. S. Procedimentos Metodológicos para Aplicação de Avaliação PósOcupação em Conjunto Habitacionais para a População de Baixa Renda: do desenho urbano à unidade habitacional. In: ABIKO, A. K.; ORNSTEIN, S. W. (Eds.). Inserção Urbana e Avaliação Pós-Ocupação (APO) da Habitação de Interesse Social, São Paulo, SP: FAUUSP, 2002. p. 211-241.

SANOFF, H. Multiple Views of Participatory Design. International Journal of Architectural Research, v. 2, n. 1, p. 57-69, mar. 2008.

TZORTZOPOULOS, P. et al. Desenvolvimento de um Modelo de Gestão para o Processo de Desenvolvimento de Produtos da Construção Civil: projeto de edificações. Porto Alegre: NORIE/UFRGS, 2000.

VISCHER, J. C. Applying Knowledge on Building Performance: from evidence to intelligence.

Intelligent Buildings International, v. 1, n. 4, p. 239-248, 2009.

WAY, M.; BORDASS, B. Making Feedback and Post-Occupancy Evaluation Routine 2: soft landings, involving design and building teams in improving performance. Building Research \& Information, v. 33, n. 4, p. 353-360, 2005.

WOODRUFF, R. B. Customer Value: the next source for competitive advantage. Journal of the Academy of Marketing Science, v. 25, n. 2, p. 139-153, 1997

WOODRUFF, R. B.; GARDIAL, S. Know Your Customer: new approaches to understanding customer value and satisfaction. [S.1.]: Blackwell Publishing, 1996.

ZEITHAML, V. A. Consumer Perceptions of Price, Quality, and Value: a means-end model and synthesis of evidence. Journal of Marketing, v. 52, p. 2-22, jul. 1988.

\section{Agradecimentos}

Os autores agradecem à Gerência de Desenvolvimento Urbano (GIDUR) da CAIXA de Porto Alegre, pela participação e pelas informações concedidas; aos envolvidos com o programa HABITARE, responsável pelo financiamento do Projeto QualiHIS; à CAPES e ao CNPq, pela bolsa de mestrado concedida; e também aos moradores dos empreendimentos estudados, por receber os pesquisadores e permitir a realização da pesquisa. 


\section{Revista Ambiente Construído}

Associação Nacional de Tecnologia do Ambiente Construído

Av. Osvaldo Aranha, $99-3^{\circ}$ andar, Centro

Porto Alegre - RS - Brasil

CEP 90035-190

Telefone: +55 (51) 3308-4084

Fax: +55 (51) 3308-4054

www.seer.ufrgs.br/ambienteconstruido

E-mail: ambienteconstruido@ufrgs.br 